Adsor pt i on For ce of Pol yani I i ne- Coat ed Pol ystyrene Lat ex Parti cles

\begin{tabular}{|l|l|}
\hline 著者 & Q ang Ke, AOK Koi chi \\
\hline $\begin{array}{l}\text { j our nal or } \\
\text { publ i cat i on ti t l e }\end{array}$ & Journal of Col I oi d and I nt er face Sci ence \\
\hline vol une & 305 \\
\hline number & 1 \\
\hline page $r$ ange & $40-45$ \\
\hline year & $2007-01$ \\
\hline URL & ht t p: //hdl . handl e. net /10098/1153 \\
\hline
\end{tabular}




\title{
Adsorption Force of Polyaniline-Coated Polystyrene Latex Particles
}

\author{
Qiang Ke and Koichi Aoki* \\ Department of Applied Physics, University of Fukui, \\ 3-9-1, Bunkyo, Fukui-shi, 910-8507 Japan
}

\begin{abstract}
Visible polyaniline-latex particles $13 \mu \mathrm{m}$ in diameter were used for obtaining quantitatively a relationship between the adsorption force and the electroactivity at a platinum electrode. The suspension in hydrochloride acid was filled in an optical cell equipped with wire electrodes. When electrode potential was switched between the oxidized and the reduced domains alternatively, some adsorbed particles showed color change owing to the electroactivity. The numbers of the electroactive and the inactive particles were counted in the suspension including poly(N-vinylpyrrolidone) (PVP). The ratio of the numbers was proportional to the concentration of PVP, as was in equilibrium. The adsorbed particles were desorbed mechanically by forced flow. The numbers of the desorbed particles did not decrease with an increase in the flow velocity until threshold values. The threshold value for the electroactive particle was 10 times larger than that for the inactive ones, corresponding to 10 times larger adsorption energy of the electroactive particles than the inactive ones. The adsorption stress was evaluated from the removal of the electropolymerized polyaniline film from the electrode. Then the adsorption area of the particle was estimated.
\end{abstract}

Key words: polyaniline, latex particles, poly(N-vinylpyrrolidone), adsorption force, suspensions

\footnotetext{
* Corresponding author, phone +81 77627 8665, fax +81 77627 8494, e-mail d930099@icpc00.icpc.fukui-u.ac.jp
} 


\section{Introduction}

Electrochemically polymerized aromatic conducting films such as polyaniline are superior to chemically polymerized films in that films with (a) highly cohesition to electrodes, (b) uniformity of film thickness, and (c) controlled thickness are obtained [1,2]. The electrochemical advantages are due to the decrease in the solubility of polyaniline near the electrode with an increase in the degree of polymerization, and hence polymer with large molecular weight is accumulated on an electrode. However, inhomogeneity has still been observed at large conducting films, exemplified by appearance of a macroscopic pattern composed of the oxidized and the reduced species with different colors $[3,4]$.

Adsorption on an electrode occurs when species has stronger interaction with the electrode than with the solvent. Consequently, the adsorbed redox species ought to bring about an electrode reaction from the thermodynamic point of view. If it does not, it may be located on inactive sites by keeping the electroactive species away from the double layer, by blocking counterions, or by generating voids. For example, vinylferrocene films copolymerized with electroinactive polymers have lost electroactivity conditionally [5-7], because hydrophobic polymers block insertion of counterions. The blocking or void formation may be apparently removed by filling the voids with conducting polymers, as for adsorption of metal nanoparticles [8-10].

The blocking can be controlled by use of surfactants in that surfactants weaken the adsorption force. Surfactants cause also desorption of electroactive species to yield micellized form. Then, it is difficult to determine whether a reaction is due to the adsorbed species or the micellzed ones. The difficulty is circumvented by using the optically detectable big redox particles [6- 17]. If the particle contains polyaniline as a redox species, the electroactivity can readily be identified by the color change $[18,19,20]$. As for a surfactant, poly (N-vinylpyrrolidone) (PVP) works well not only as a steric stabilizer for polyaniline [21-23] 
but also as enhancement of processability of polyaniline $[24,25]$. The combination of polyaniline latex with PVP may be suitable for the investigation of the relation between the adsorbability and the electrode reaction. We here use the mono-dispersed polyaniline-coated polystyrene latex (PANI-PS) as an optically detectable redox particle, and obtain the relationship between the redox activity of the adsorbed particle and adsorption force in the presence of PVP. We employ the forced flow of the solution for the estimation of the adsorption force, following the imaging processing by an optical microscope under hydrodynamic control [26-30].

\section{Experiment}

\subsection{Chemicals and synthesis}

Styrene (Wako) was purified by distillation under vacuum at $60^{\circ} \mathrm{C}$ and stored in a refrigerator until use. Poly (N-vinyl pyrrolidone) (PVP) (Wako) with $360 \mathrm{~kg} \mathrm{~mol}^{-1}$ was used as a surfactant at the dispersion-polymerization of styrene. 2, 2'-Azoisobutyronitrile (AIBN) (Kanto) was used as an initiator of the polymerization for latex seeds. Ethanol (99.5 \%, Wako), 2-methoxyethanol (Wako), ammonium peroxydisulfate (Kanto), aniline hydrochloride (Kanto), and 2-propanol were used as received. All aqueous solutions were prepared with deionized water.

The synthetic procedure of the PANI-PS latex has been described in ref.20. The size and morphology were examined with a scanning electron microscope, S2400 (Hitachi).

\subsection{Electrochemical flow cell}

The electrochemical flow cell consisted of two glass plates for the flowing space of 15 mm wide and $0.05 \mathrm{~mm}$ thick, which led to an inlet and an outlet, as is shown in Fig.1. The two plates sandwiched three platinum wire electrodes $0.03 \mathrm{~mm}$ in diameter, and were fixed 
with the plastic block by epoxy resin. The flow cell was mounted horizontally in a digital microscope, VMS-1900 (Scalar). The PANI-PS aqueous suspension containing 0.5M HCl was filled in the cell. Video of PANI-PS particles close to the Pt working electrode were recorded during the square-wave potential application between 0.5 and $-0.2 \mathrm{~V}$ by use of a potentiostat, HECS-1112 (Fuso, Kawasaki). Further amount of the suspension was injected into the flow cell at various flow rates. A series of time-varying images of the video were saved in mpeg files, which were decomposed into 30 frames a second in JPEG files. Each frame of an image had $720 \times 480$ pixels.

\subsection{Measurement of adsorption force of polyaniline film}

Adsorption force of a polyaniline film was obtained with the home-made apparatus equipped with a balance, GX-200 (A \& D Comp.) and the electrochemical cell, as is shown in Fig. 2. The cell was supported with a controllable lifter. The platinum plate leading to a copper wire was coated with epoxy resin so that a given area (typically $4 \times 12 \mathrm{~mm}^{2}$ ) was exposed to solution. The polyaniline film was electrochemically deposited on the exposed area by means of cyclic potential scan between 0 and $0.9 \mathrm{~V}$ vs. Ag|AgCl

The face of the platinum plate opposite to the polyaniline film electrode was fixed on the bottom of the cell with double side adhesive tape. The stripped area of the polyaniline film was controlled with by a given area of the adhesive tape. The polyaniline film was connected to a string with adhesive tape. The string reached the arm of the balance, which led to a weight on the electronic balance. Potential of $0.5 \mathrm{~V}$ vs. $\mathrm{Ag} \mid \mathrm{AgCl}$ was applied to the electrode and then the lifter was lowered at a given speed until the polyaniline film was detached from the platinum plate. A read of the balance just before the detachment was recorded.

\section{Results and Discussion}

\subsection{Electroactivity of adsorbed PANI-PS particles}


The polyaniline-coated polystyrene latex (PANI-PS) particles, showing dark green, were almost spherical. The average diameter was $2 a=13.03 \pm 0.12 \mu \mathrm{m}$ evaluated from SEM. Although the polystyrene-core was synthesized by growing from seed iteratively, it was kept nearly mono-dispersed, as shown in Fig. 3. Its suspension in $0.01 \mathrm{~g} \mathrm{~cm}^{-3} \mathrm{PVP}$ and $0.5 \mathrm{M} \mathrm{HCl}$ was stable for at least two years.

When a platinum wire was inserted into the suspension, a part of the electrode surface was coated with the particles. When cyclically scanned potential was applied to the electrode, we observed a color change of the electrode surface; being dark green at potential more than $0.4 \mathrm{~V}$ vs. Ag|AgCl and pale green at potential less than $0.0 \mathrm{~V}$ vs. Ag|AgCl (Fig. 4). Since this color change was very close to the change in electrochemically polymerized polyaniline films [18-20], it should be due to the electrode reaction of adsorbed PANI-PS particles. In general, the use of polymeric stabilizers lowers not only the electrical conductivity [31] but also electroactivity of PANI. The particles were still adsorbed against a water jet by a washing bottle. There was no gravitational effect on the adsorption.

Addition of the surfactant (PVP) in the suspension is expected to make the particles desorbed from the electrode. Since PVP was included latently in the PANI-PS particles for avoiding aggregation of the particles, sufficient control of concentration of PVP in the suspensions requires exhaustive removal of PVP from the inside of the particles. Therefore the particles were rinsed with $0.5 \mathrm{M} \mathrm{HCl}$ solution 3 times, and then redispersed in $0.5 \mathrm{M} \mathrm{HCl}$ solution containing a given concentration of PVP. The color of polyaniline on the Pt wire became darker as the concentration of PVP decreased, suggesting an increase in the adsorption. In order to obtain quantitative data of the adsorption, we counted the number of the adsorbed particles in the PVP-included suspension in the thin layer cell with the glass window (Fig. 1). When the square-wave potential sequence between -0.2 and $0.5 \mathrm{~V}$ at $0.5 \mathrm{~Hz}$ was applied to the electrode, some adsorbed particles changed the color synchronizing with a change in the potential, and some didn't, as shown in Fig. 4. The former is electroactive and 
the latter is electroinactive. The electroactive particles did not change into the electroinactive ones at least during $30 \mathrm{~s}$ alternative potential-application, and vice versa.

As a quantitative evaluation of the extent of the color change, we counted the number of the electroinactive particles, $n_{\mathrm{I}}$, and that of the electroactive particles, $n_{\mathrm{A}}$, for 10 experimental runs by the video. Approximate values of $n_{\mathrm{A}}$ and $n_{\mathrm{I}}$ were over 500 . We plotted the ratio of $n_{\mathrm{I}} / n_{\mathrm{A}}$ against the concentration of PVP in Fig. 5. A linear relationship was found. PVP generally micellizes hydrophobic species, S, to yield hydrophilically micellized one, S(PVP), through the reaction

$\mathrm{S}+\mathrm{PVP} \leftrightarrow \mathrm{S}(\mathrm{PVP})$

The equilibrium constant is given by

$K=[\mathrm{S}(\mathrm{PVP})] /[\mathrm{S}][\mathrm{PVP}]$

If [S] is taken to be the hydrophobic area of the PANI-PS particles instead of concentration of $\mathrm{S}$, then $[\mathrm{S}(\mathrm{PVP})]$ corresponds to the hydrophilic area of the PANI-PS particles. The hydrophobic part should come in stronger contact with the electrode in the aqueous solution than the hydrophilic part. The latter is more electroactive than the former because of blocking the electron transfer by the surfactant, as is illustrated in Fig. 6. Then [S] and [S(PVP)] are, respectively, equivalent to $n_{\mathrm{A}}$ and $n_{\mathrm{I}}$. Since the amount of PVP consumed by S(PVP) is much smaller than the loaded amount of PVP, Eq. (2) is approximated as

$$
n_{\mathrm{I}} / n_{\mathrm{A}}=K c
$$

where $c$ is the concentration of PVP in the suspension. This equation is close to the plot in Fig. 5. The equilibrium constant, the slope in Fig. 5, is $31 \mathrm{~cm}^{3} \mathrm{~g}^{-1}$ or $1.1 \times 10^{4} \mathrm{M}^{-1}$, through which the electrochemical activity is controllable by concentration of PVP. The plot has a small intercept, indicating that even zero concentration of PVP might allow the adsorbed particles to be electroinactive. The suspended particles necessarily contain the surfactant on the surface. Otherwise, it might aggregate. One-tenth $\left(n_{\mathrm{I}} / n_{\mathrm{A}}=0.1\right.$ at $\left.c=0\right)$ of the surfactant may be coated latently with PVP on the surface. 
The electroactive particles kept their electroactivity for a long time, and the electroinactive ones also did the inactivity, as if there would be essentially two kinds of particle with different chemical structures. If the color-changed particles were to sometimes change accidentally into the color-unchanged particles, the true equilibrium might hold. The equilibrium-like behavior in Fig. 5 indicates that the redox states should be fixed after the adsorption to yield irreversible activity.

\subsection{Adsorption force}

Our presumption is that the electroactivity is relevant strongly to the adsorption force. The electroactivity was with the color change by the electrochemical reaction, whereas the adsorption force has not been evaluated and lies just in a concept. We tried to estimate the adsorption force hydrodynamically by sweeping the adsorbed particles away from the electrode with forced flow. The flow cell was filled with the suspension, and the square-wave potential sequence was applied to the electrode of which color change was monitored with the video microscope. The additional suspension was injected to the cell at such pressure that some more adsorbed particles were swept away from the electrode. The digital video file was divided into photographic frames taken at each $33 \mathrm{~ms}$. Locations of a swept particle were traced at the succeeding photographs. The flow velocity at which an adsorbed particle was detached was calculated from the difference in the locations at two succeeding photographs divided by 33ms. Thus the flow velocity here denotes the swept away-velocity.

We define $n_{\mathrm{A}}$ and $n_{\mathrm{I}}$ in the flow experiment as the numbers of the electroactive (with color change) and the electroinactive (without color change) particles retained on the electrode at the swept away-velocity, $v$. We counted $n_{\mathrm{I}}$ and $n_{\mathrm{A}}$ at various values of $v$, and plotted the sum of $n_{\mathrm{I}}$ over 10 runs and that of $n_{\mathrm{A}}$ over 10 runs against $v$ in Fig.7. Since $n_{\mathrm{I}}$ and $n_{\mathrm{A}}$ are the total numbers of at the velocity less than $v$, the plot contained small scattering. 
These values did not vary with $v$ at slow velocity and decreased almost linearly with $v$ over the critical flow velocity, $v_{\mathrm{c}}$. A difference of $n_{\mathrm{I}}$ at $v=0$ from $n_{\mathrm{I}}$ at $v>v_{\mathrm{C}}$ is the number of particles swept away. Values of $v_{\mathrm{c}}$ decreased with an increase in the concentration of PVP, as is shown in Table 1. A value of $v_{\mathrm{c}}$ for the electroactive particles, $\left(v_{\mathrm{c}}\right)_{\mathrm{A}}$, was always ca. 10 times larger than that for the electroinactive ones, $\left(v_{\mathrm{c}}\right)_{\mathrm{I}}$.

The sudden variation of $n_{\mathrm{I}}$ or $n_{\mathrm{A}}$ at $v_{\mathrm{c}}$ implies that the detachment of an adsorbed particle requires the activation energy, $U$, of the adsorption force by the flow. The frictional force acting on a sphere with radius $a$ in the medium with the viscosity $\eta$ is given by the Stokes' force, $6 \pi \eta a v$. This force gives approximately the moment $6 \pi \eta a^{2} v$ to the center of the particle to rotate the particle on the electrode. The particle is desorbed from the electrode when the energy by the flow overcomes $U$. Then the effective activation energy is $U-A_{1} \eta a^{2} v$, where $A_{1}$ is a constant. The probability of being desorbed from the electrode has exponential variation of the effective activation energy, given by

$\left(n_{v=0}-n_{v>v c}\right) / n_{v=0}=A_{2} \exp \left[-\left(U-A_{1} \eta a^{2} v\right) / R T\right]$

where $n$ stands for either $n_{\mathrm{I}}$ or $n_{\mathrm{A}}$, and $A_{2}$ is a constants. Expanding the exponential of $\left(U-A_{1} \eta a^{2} v / R T\right)$ yields approximately

$n_{v>v_{\mathrm{c}}} / n_{v=0}=1-A_{2} \exp \left[-\left(U-A_{1} \eta a^{2} v\right) / R T\right] \approx 1-A_{2}(1-U / R T)-A_{1} A_{2} \eta a^{2} v / R T+\Lambda$

This equation shows the linear decrease in $n_{v>v c}$ with $v$. The linearity was found in the experimental results in Fig. 7. The Stokes' forces at $\left(v_{\mathrm{C}}\right)_{\mathrm{I}}=0.12 \mathrm{~mm} \mathrm{~s}^{-1}$ and $\left(v_{\mathrm{c}}\right)_{\mathrm{A}}=1.1 \mathrm{~mm} \mathrm{~s}^{-1}$ are, for example, $120 \mathrm{pN}$ and $12 \mathrm{pN}$, respectively, for $\eta=0.89 \mathrm{~g} \mathrm{~m}^{-1} \mathrm{~s}^{-1}$ of water at $25^{\circ} \mathrm{C}$. Since values of $A_{1} \eta a^{2} v$ near the critical velocity are close to the value of the activation energy, $v_{\mathrm{C}}$ is a measure of the activation energy. The relation of $\left(v_{\mathrm{c}}\right)_{\mathrm{A}}=10\left(v_{\mathrm{c}}\right)_{\mathrm{I}}$ in Table 1 mentions that the activation energy of the electroactive particles is estimated to be ten times larger than that of the electroinactive ones.

If the adsorption force per unit area is available, we can estimate the area actually contributing to the adsorption. We attempted to obtain a relation between the adsorption force 
and the area for an electrochemically polymerized polyaniline film by measuring the force removing the film from the platinum plate by means of the home-made balance (Fig. 2). The area of the film was controlled by shielding the electrode surface with adhesive tape. The adsorption force was measured during the $0.5 \mathrm{~V}$ vs. Ag|AgCl potential application, according to the procedure described in the experimental section. Three runs were made at each polyaniline film, and three forces were averaged. The adsorption force was plotted against the area of polyaniline film in Fig. 8. A linear relationship was found although there was as large as scattering of $18 \%$ in the slope. The intercept of the plot, which should not appear ideally, may be ascribed to the inertial force of the arm, the weight, and the film. The slope, $34 \pm 6$ $\mathrm{mN} \mathrm{mm}^{-2}$, is the net adsorption stress. Applying this value to the adsorption force, for example, $120 \mathrm{pN}$, of the electroactive particle, we obtained the area of the adsorption per particle, $120 \mathrm{pN} / 34 \mathrm{mN} \mathrm{mm}^{-2}=3500 \pm 630 \mathrm{~nm}^{2}$. This area corresponds to a disk $66 \pm 7 \mathrm{~nm}$ in diameter, being a part of the spherical surface adsorbed on the electrode. It is equivalent to $6.4 \times 10^{-6}$ steradian, implying an actual point touch with the electrode. Since we are interested in getting an image of the adsorption of a big particle, we are concerned with only the order of the size of an adsorbed disk ( $1 \mu \mathrm{m}$ or $0.1 \mu \mathrm{m})$ rather than the accurate value (66 nm). For this purpose, this adsorption force measurement is enough in spite of the large experimental errors. The adsorption force for the reduced PANI could not be obtained because the reduced film was detached from the electrode during mounting the film before applying force to the film.

According to Table 1, the critical velocity decreases with an increase in the concentration of PVP. We found that the velocity for both the electroactive and the electroinactive particles showed a linear relation with $\log (c)$, as is shown in Fig. 9. The two regressed lines meet at the common intercept on the $\log (c)$ axis for $c_{0}=0.029 \mathrm{~g} \mathrm{~cm}^{-3}(0.082 \mathrm{mM})$. Particles can be removed spontaneously for $c>c_{0}$ whereas they cannot be for $c<c_{0}$. Therefore $c_{0}$ is a critical concentration, like a critical micelle concentration (CMC). The variations in Fig. 9 are similar to a big change in physical properties at a CMC [32]. The common value of the CMC for the 
electroactive and the electroinactive particles indicates that the amount of PVP adsorbed on the electroactive particles is the same as that of the electroinactive ones.

\section{Conclusion}

Some of the PANI-PS particles adsorbed on the electrode showed color change of PANI responding to the alternate switch of the electrode potential, and some did not. The ratio, $n_{\mathrm{I}} / n_{\mathrm{A}}$, increased with an increase in the concentration of PVP, according to the equilibrium of the micellization. The equilibrium suggests quantitative control of the adsorption of big particles. A model of representing the relation between the electroactivity and the concentration of PVP is partial blocking of the PANI surface of particles with PVP. The variation of $n_{\mathrm{I}} / n_{\mathrm{A}}$ with [PVP] is the quantitative demonstration that the adsorbed species is not always electroactive. The equilibrium holds even for the macroscopic particles through the molecular equilibrium.

Dynamic desorption was evaluated by counting the electroactive and the electroinactive particles swept away by the flow. Values of $n_{\mathrm{I}} / n_{\mathrm{A}}$ were kept to the equilibrium at slow flow velocity. They decreased linearly with an increase in the velocity over the critical velocity. The sudden decrease at $v_{\mathrm{c}}$ suggests an activation process of the desorption. The critical velocity for the electroactive particle was ten times larger than that for the electroinactive one. This fact implies the ten times stronger adsorption force for the electroactive particle than that for the inactive one. The electroactivity was demonstrated quantitatively to be related closely with the adsorption force. The critical velocity decreased logarithmically with an increase in the concentration of PVP, and reached zero at $0.082 \mathrm{mM}$ both for the electroactive and the electroinactive particles. This is a kind of the critical concentration over which the particles are not adsorbed dynamically.

\section{Acknowledgement}


This work was financially supported by Grants-in-Aid for Scientific Research (Grants 18350041) from the Ministry of Education in Japan.

\section{References}

[1] A. F. Diaz, J. F. Rubinson, H. B. Mark, Jr., Advances in Polymer Science, 84, Electronic Applications, pp.114-131, Springer-Verlag, Berlin, 1988.

[2] G. P. Evans, Advances in Electrochemical Science and Engineering, Vol. 1, edited by H.

Gerischer and C. W. Tobias, VCH Publishers Inc., New York, 1990.

[3] T. F. Otero, H.-J. Grande, J. Rodríguez, J. Phys. Chem. B 101 (1997) 3688.

[4] K. Aoki and Y. Teragishi, J. Electroanal. Chem. 441 (1998) 25.

[5] I. Jureviciute, S. Bruckenstein, A. R. Hillman, J. Electroanal. Chem. 488 (2000) 73.

[6] J. Chen, C. Xu, K. Aoki, J. Electroanal. Chem. 546 (2003) 79.

[7] C. Xu, J.Chen, K.Aoki, Electrochem. Commun. 5 (2003) 506.

[8] E. Pintér, R. Patakfalvi, T. Fülei, Z. Gingl, I. Dékány, C. Visy, J. Phys. Chem. B 109 (2005) 17474.

[9] N. Cioffi, L. Torsi, L. Sabbatini, P. G. Zambonin, T. Bleve-Zacheo, J. Electroanal. Chem. 488 (2000) 42.

[10] H. Srikanth, P. Poddar, J. L. Wilson, K. Mohomed, J. P. Harmon, Proc. Mater. Res. Symp. 2004, 788

[11] K. Aoki, T. Lei, Langmuir 16 (2000) 10069.

[12] Y. Gao, J. Chen, J. Electroanal. Chem. 578 (2005) 129.

[13] J. Chen, Z. Zhang, J. Electroanal. Chem. 583 (2005) 116.

[14] Y. Gao, J. Chen, J. Electroanal. Chem. 583 (2005) 286.

[15] L. Han, J. Chen, I. Ikeda, Chemistry letters, 34 (2005) 1512.

[16] C. DeArmitt, S. P. Armes, J. Colloid Interface Sci. 150 (1992) 134.

[17] K. Aoki, C. Wang, Langmuir 17 (2001) 7371.

[18] T. Kobayashi, H. Yoneyama, H. Tamura, J. Electroanal. Chem. 177 (1984) 293.

[19] K. Aoki, J. Chen, Q. Ke, S. P. Armes, D. P. Randall, Langmuir 19 (2003) 5511. 
[20] K. Aoki, Q. Ke, J. Electroanal. Chem. 587 (2006) 86.

[21] J. Huang, H. Zhang, J. Hou, P. Jiang, Reactive \& Functional Polymers 53 (2002) 1.

[22] Q. Ye, X. Zhang, C. Xu, W. Ge, Z. Zhang, Colloid. Surf. A 226 (2003) 69.

[23] S. Komarneni, D. Li, B. Newalkar, H. Katsuki, A. S. Bhalla, Langmuir 18 (2002) 5959.

[24] N. K. Svelko, S. Reynaud, J. Francois Synthetic Metals 150 (2005) 107.

[25] J. Stejskal, P. Kratochvil, Langmuir 12 (1996) 3389.

[26] Z. Adamczyk, E. Musia, B. Siwek, J. Colloid Interface Sci. 269 (2004) 53.

[27] Z. Adamczyk, E. Musia, B. Jachimska, L. S.-Warszyska, A. Kowalf, J. Colloid Interface Sci. 254 (2002) 283.

[28] A. I. Abdel-Fattah, M. S. El-Genk, P. W. Reimus, J. Colloid Interface Sci. 246 (2002) 241.

[29] J. M. Meinders and H. J. Busscher, Langmuir, 11 (1995) 327.

[30] Y. L“uthi, J. Ri`cka, J. Colloid Interface Sci. 206 (1998) 302.

[31] S. Shreepathi, R. Holze, Langmuir 22 (2006) 5196.

[32] L. I. Osipow, Surface Chemistry, Reinhold Publishing Corp. 1962, 185-191. 
